\title{
A RETÓRICA DA LINGUAGEM CIENTÍFICA: DAS BASES TEÓRICAS À ELABORAÇÃO DE MATERIAL DIDÁTICO PARA O ENSINO SUPERIOR DE QUÍMICA
}

\author{
Jane Raquel Silva de Oliveira \\ Universidade Federal de São Carlos, Rod. Washington Luiz, km 235, 13565-905 São Carlos -SP, Brasil \\ Salete Linhares Queiroz* \\ Instituto de Química de São Carlos, Universidade de São Paulo, CP 780, 13560-970 São Carlos - SP, Brasil
}

Recebido em 22/6/11; aceito em 1/11/11; publicado na web em 13/1/12

\begin{abstract}
SCIENTIFIC LANGUAGE RHETORIC: FROM THE THEORETICAL BASIS TO THE PRODUCTION OF DIDACTIC MATERIAL FOR UNDERGRADUATE CHEMISTRY TEACHING. This work is part of a study that focused on analyzing the contributions of didactic activities related to scientific language rhetoric characteristics aimed at developing students' abilities to identify such characteristics in chemistry scientific texts and critical reading of those texts. In this study, we present the theoretical basis adopted to determine the scientific discourse characteristics and for the production of the didactic material used in those activities. Latour, Coracini and Campanario studies on persuasive rhetorical strategies present in scientific articles aided the production of such material.
\end{abstract}

Keywords: scientific language; rhetoric; didactic material.

\section{INTRODUÇÃO}

A comunicação é um processo social: comunicamo-nos melhor com pessoas que são membros da nossa própria comunidade, isto é, com aqueles que utilizam a linguagem na mesma forma que nós a empregamos. Nesse sentido, o ensino de ciências deve ser visto como um processo social no qual o estudante é introduzido dentro desta comunidade de pessoas que "falam ciência" e compartilham significados específicos. ${ }^{1}$ Essa perspectiva tem colocado em destaque o papel da linguagem científica para a prática e para o aprendizado de ciências, bem como impulsionado diversas pesquisas sobre essa temática na área de educação em ciências. ${ }^{2-5}$

A reconhecida importância da linguagem para a educação em ciências também se reflete nas atuais Diretrizes Curriculares Nacionais para os Cursos de Química, as quais apontam para a necessidade dos estudantes aprenderem a "ler, compreender e interpretar os textos científico-tecnológicos", "escrever, apresentar e defender seus achados", "saber comunicar corretamente os projetos e resultados de pesquisa na linguagem científica", dentre outras. ${ }^{6}$

Apesar de tais recomendações, poucos trabalhos têm sido produzidos no país no sentido de aprimorar a escrita científica de estudantes do ensino superior de Química e habilitá-los na leitura crítica de textos científicos. ${ }^{7,8}$ Cabe destacar que estes trabalhos, bem como outros produzidos no exterior nesta perspectiva, enfatizam somente os aspectos estruturais e as características dos textos científicos mais aceitas e difundidas pela comunidade científica. ${ }^{9}$

Além disso, os livros ou manuais de redação científica para estudantes de graduação da área de Ciências Naturais também priorizam aspectos dessa natureza: em geral, os materiais de apoio aos alunos para a produção de textos científicos tratam de características estruturais, tais como a organização do texto em seções típicas, padronização de citações e referências, apresentação de tabelas e gráficos etc. ${ }^{10} \mathrm{Em}$ alguns casos, esses materiais procuram também auxiliá-los na compreensão de algumas das características da linguagem científica que são mais aceitas e recomendadas pela comunidade científica, como

*e-mail: salete@iqsc.usp.br a impessoalidade, clareza, continuidade, uso dos tempos verbais nos textos científicos etc. ${ }^{11,12}$

"Sabe-se, no entanto, que ler (e mesmo redigir) um texto científico não significa apenas conhecer e utilizar sua forma". ${ }^{13}$ A apropriação da linguagem científica requer também uma compreensão mais clara e profunda dos recursos linguísticos empregados pela comunidade científica na construção dos textos, ou seja, uma análise de suas características retóricas. ${ }^{14,15}$ Sob esse aspecto, Coracini ${ }^{13}$ relata que os alunos, em geral, adotam uma postura passiva diante dos textos científicos com os quais se deparam, raramente questionando-os quanto ao conteúdo ou conclusões apresentadas pelo autor. Assim, para que se possa compreender a linguagem científica é necessária a realização de uma análise crítica de uma série de práticas adotadas pelos cientistas na elaboração do texto científico. Tais considerações revelam, portanto, a importância de estudos nos quais as características retóricas da linguagem científica sejam objeto de discussão no contexto do ensino superior de química - e de outros cursos de ciências -, bem como a produção e aplicação de materiais didáticos que auxiliem os alunos no reconhecimento de tais aspectos e na leitura crítica de textos de sua área.

Diante desse cenário, elaboramos um material didático (disponibilizado como material suplementar) sobre aspectos retóricos da linguagem científica com o intuito de auxiliar os estudantes de graduação no desenvolvimento de habilidades de identificação de estratégias de linguagem empregadas pelos cientistas e de leitura crítica de textos científicos da área de Química. Além da apresentação de características retóricas da linguagem, elaboramos questões na tentativa de estimular os estudantes a identificar tais características em textos científicos e a refletir criticamente sobre elas. É ainda importante esclarecer que outro material didático, destinado, porém, à discussão de algumas das características estruturais da linguagem científica, foi por nós publicado recentemente nesta revista, também no formato de material suplementar. ${ }^{16}$

Neste artigo, apresentamos as bases teóricas adotadas para o delineamento de características retóricas do discurso científico e para a elaboração do referido material didático. Acreditamos que o reconhecimento de tais aspectos da linguagem científica e sua introdução no ensino superior de Química a partir do material proposto 
possam ser úteis para os graduandos, no sentido de alcançarem uma visão mais adequada da literatura científica e tomarem decisões conscientes quanto ao uso dos recursos retóricos na elaboração de textos científicos.

\section{REFERENCIAIS TEÓRICOS PARA A CARACTERIZAÇÃO DE ASPECTOS RETÓRICOS DO TEXTO CIENTÍFICO}

Para a caracterização do discurso científico que subsidiou a produção do material didático, adotamos as considerações apresentadas por Latour, ${ }^{14}$ Coracini $^{13}$ e Campanario ${ }^{15}$ em trabalhos nos quais discutem diversos aspectos retóricos da linguagem científica. Com base nesses trabalhos, apresentamos a seguir uma caracterização do discurso científico, destacando algumas das sutis estratégias empregadas pelos cientistas para convencer o leitor da relevância e do rigor de suas pesquisas.

\section{Padronização rígida da organização textual}

Um dos aspectos mais característico do discurso científico é a padronização rígida de sua organização textual. Mesmo quando não há uma imposição explícita (pela revista, instituição, agência de fomento, congresso etc.) das normas às quais o texto deve se adequar, o autor ainda se mantém fiel a uma certa padronização frequentemente seguida pela comunidade científica. Com tal recurso, o autor demonstra ao leitor que é um membro dessa comunidade e hábil conhecedor das regras estabelecidas por ela, o que facilita a aceitação de seu trabalho pelos pares. ${ }^{13}$

Além disso, na perspectiva da Análise do Discurso, as manifestações linguísticas não se apresentam de forma isolada das demais: os textos estabelecem relação com outros textos anteriormente produzidos, em conformidade ou em oposição a um esquema textual pré-existente. Assim, todo texto, ao apresentar elementos também presentes em outros textos, traz consigo fragmentos de sentidos já conhecidos do leitor, facilitando, dessa forma, seu processo de leitura. ${ }^{13}$

Portanto, a obediência às normas de apresentação textual é uma característica do discurso científico que, embora possa indicar a objetividade da ciência, revela também, ainda que sutilmente, uma estratégia de persuadir o leitor a dar crédito ao autor. No texto, essa característica manifesta-se das seguintes maneiras: a) divisão em seções típicas e em sequência definida. A padronização das seções, além de situar o leitor em "ambiente" já conhecido, possibilita que ele vá direto à seção que lhe interessa; b) limitações quanto ao tamanho do texto e padronização na forma de apresentação das citações e referências bibliográficas. Os sistemas de citações e referências bibliográficas, embora possam ser ligeiramente distintos, guardam entre si semelhanças que os fazem ser facilmente compreendidos pelo leitor; c) padronização na forma de apresentação de figuras, tabelas e suas legendas. $\mathrm{O}$ emprego de uma estrutura quase sempre similar, de modo que o leitor possa não apenas fazer uma rápida análise de seu conteúdo, mas, eventualmente, realizar uma comparação com outras tabelas e figuras que expressam dados correlacionados, facilita a leitura e aceitação do texto.

\section{Não reprodutibilidade das etapas de elaboração textual}

A sequência típica das seções na qual o discurso científico é geralmente apresentado pode induzir o leitor a imaginar que o processo de redação de cada seção do texto também segue essa ordem característica. Frequentemente não é isso que ocorre: o autor elabora cada seção do texto em uma sequência bem distinta daquela comumente apresentada nos artigos científicos. ${ }^{13}$
A não reprodutibilidade do processo de elaboração textual é uma característica do discurso científico que, embora seja reconhecida e até mesmo recomendada pela comunidade científica, não se evidencia no texto de forma clara, uma vez que o autor não costuma deixar "pistas" sobre o caminho trilhado durante a redação de cada seção do texto. Tal característica deixa transparecer a importância dada ao leitor durante o processo de elaboração textual. Assim, a estrutura típica dos textos científicos é moldada de forma a garantir uma leitura linear, lógica e agradável para o leitor, pouco importando o caminho percorrido pelo autor em sua elaboração. ${ }^{13}$

\section{Ausência de subjetividade}

A ciência pretende se revelar através do discurso como objetiva, imparcial e neutra. Daí a ausência de subjetividade como uma das características típicas dos textos científicos. Esse aspecto do discurso científico é tão importante para a própria comunidade científica que frequentemente os guias sobre como escrever e publicar artigos científicos ressaltam o caráter impessoal do texto e aconselham o autor a não se envolver pessoalmente com o mesmo. ${ }^{15}$ Dessa forma, dentro das convenções da comunidade científica, o autor assume no texto a postura de mero observador, distante do objeto de pesquisa, apenas relatando os resultados dela proveniente. Essa imagem de imparcialidade do autor do discurso sugere ao leitor a ausência de opiniões e interesses pessoais do pesquisador, garantindo credibilidade à pesquisa relatada. ${ }^{13}$

A ausência de subjetividade é uma das características mais aceitas e divulgadas do discurso científico e manifesta-se no texto através de recursos, como o emprego de tempos verbais na voz passiva. Assim, permanece a ideia central de que o autor do artigo evita fazer referência a si próprio como agente das ações relatadas no texto, através do apagamento do sujeito enunciador no texto ou deixando que os objetos, os fatos, falem por si. Portanto, mesmo quando o texto faz menção às atividades próprias do pesquisador (realizar, proceder, concluir), é possível, dentro do discurso, ocultar o agente do processo, isto é, 'camuflar a 'origem enunciativa': afinal, aparentemente é o enunciado quem diz, o fato que se apresenta e não o sujeito enunciador". ${ }^{13}$

Cabe destacar que, contrariando sua imagem de objetividade, o discurso científico também revela marcas linguísticas de subjetividade, como a sutil presença dos autores. Segundo Campanario, ${ }^{15}$ ainda que o discurso científico seja mais impessoal que outros tipos de discurso, os autores não desaparecem como um todo: estão ali, argumentando sutilmente e orientando o leitor para que siga o caminho que conduz às interpretações que desejam transmitir. Campanario ${ }^{15} \mathrm{e}$ Coracini ${ }^{13}$ apontam a presença do autor em várias situações no texto científico, tais como:

a) quando eventualmente se revela através de pronomes pessoais. Revela-se geralmente por meio do uso do pronome "nós" em detrimento do "eu", o que evidencia outro aspecto do discurso científico: o compartilhamento com outros pesquisadores (geralmente de seu grupo) da responsabilidade pela informação apresentada;

b) quando o autor assume sua pesquisa justificando a escolha do tema ou do material. Os motivos que despertam o interesse de um cientista por um dado tema ou material de pesquisa estão, em geral, atrelados aos seus interesses particulares e seu percurso acadêmico. Ao justificar sua pesquisa, o autor assume seus interesses e, dessa forma, revela-se ao leitor;

c) quando o autor admite algumas limitações da pesquisa. Nesse caso, a presença do autor pode ser percebida quando expõe sua ignorância sobre determinado assunto ou reconhece dificuldades durante a realização da pesquisa; 
d) quando o autor avalia a ocorrência de um fenômeno ou resultado (manifesta um juízo de valor). A avaliação pessoal do autor a respeito de dados e observações de seu próprio trabalho ou de outra pesquisa pode ser observada quando manifesta um juízo de valor. Assim, ao realizar um julgamento sobre os dados da pesquisa, o autor revela-se no texto;

e) quando o autor faz hipóteses, sugestões. Os resultados de pesquisa por si só não "dizem" suas possíveis explicações. A presença de hipóteses ou sugestões revela um autor que vai além do simples relato da pesquisa, ele apresenta sua interpretação pessoal;

f) quando o autor sugere novas pesquisas. A indicação explícita de novas possibilidades de estudo relacionadas à pesquisa apresentada evidencia o caráter criativo do pesquisador, dessa forma, revelando-o;

g) quando o autor faz um apelo direto ao leitor usando formas imperativas. Esse aspecto não apenas denuncia a presença do autor, mas remete à outra característica: todo discurso científico pressupõe a existência de um leitor/ouvinte virtual e, por esse motivo, direciona-se a esse leitor, como discutido a seguir.

\section{Direcionamento ao leitor/ouvinte}

Embora idealmente o autor do discurso científico seja imparcial, tão somente cumprindo a função de relatar a pesquisa de forma neutra, sem influências externas, o fato é que o interlocutor se faz presente na consciência do autor e, dessa forma, o texto apresenta elementos que denunciam o direcionamento do discurso científico a seu leitor imaginário.

Esse aspecto do discurso científico se manifesta no texto das seguintes maneiras: ${ }^{13,15}$

a) através do direcionamento explícito do discurso ao leitor, o que demonstra a importância a este atribuída na construção e apresentação do trabalho;

b) através do uso de expressões para chamar a atenção do leitor, nas quais o autor destaca, por exemplo, pontos de interesse de sua pesquisa, geralmente os aspectos positivos, que não gostaria que passassem desapercebidos pelo leitor;

c) através do uso de instruções ou diretrizes, recurso no qual o autor solicita uma ação por parte do leitor, de forma que este seja levado a interpretar os dados da mesma maneira que o autor.

\section{Pressuposta existência de contra-argumentos}

A análise de textos científicos evidencia que o autor tenta prever as objeções do leitor e, dessa forma, antecipa suas respostas. ${ }^{14}$ Coracini ${ }^{13}$ ressalta que "é em função daquilo que pensa poderem ser os argumentos contrários que ele [o autor] estabelece a sua demonstração".

Segundo Latour, ${ }^{14}$ diante do cenário de possíveis contra-argumentos os autores costumam fazer uma importante questão: "que tipo de objeções deve ser levado em conta?" As respostas, porém, não são únicas e dependem do campo de batalha; "a única regra é perguntar ao leitor (imaginário) que tipo de provas ele exigirá antes de acreditar no autor". Assim, inúmeros recursos e informações são acrescentados ao texto para ter seu trabalho aceito por seus pares, diante de todas as possíveis contestações do leitor.

\section{Alternância entre assertividade e atenuação nas afirmações}

Segundo Campanario, ${ }^{15}$ contrariando uma visão de segurança absoluta que identifica o método científico como uma receita quase infalível e que produz conhecimentos seguros, a realidade que frequentemente acompanha o discurso é bem outra: os autores apresentam com cautela os resultados, interpretações e observações da pesquisa.
A vantagem desse recurso retórico? Serve como escudo - ou, no dizer de Latour, ${ }^{14}$ como uma "apólice de seguros" - diante de possíveis erros ocorridos no trabalho ou interpretações incoerentes. Porém, segundo Latour, ${ }^{14} \mathrm{o}$ discurso científico não se constitui apenas em atenuações: o autor determina no texto o que considera ser passível ou não de discussão. Sempre que estiver tratando de assuntos consolidados, não há meias afirmações; quando, no entanto, o terreno é perigoso proliferam-se as afirmações atenuadas. Assim, "é impossível dizer que a literatura técnica sempre deriva para o lado da cautela; ela também deriva para o lado da audácia; ou melhor, não deriva; ziguezagueia por entre obstáculos e avalia os riscos da melhor maneira possível".

A assertividade pode se apresentar em diversas partes do texto, mas se revela principalmente na apresentação dos dados da pesquisa, sobretudo quando estão dispostos na forma de gráficos, imagens e tabelas. Afinal, não se trata de uma especulação, mas da demonstração de um dado concreto, obtido, visualizado. Por outro lado, as interpretações decorrentes desses dados, em geral, "derivam para o lado da cautela". ${ }^{14}$

A cautela evidencia-se no texto através da utilização de verbos no futuro do pretérito, sugerindo que o autor não quer se comprometer demais com as próprias observações e conclusões. Outro recurso é a utilização de expressões que denotam incerteza da informação proferida, as quais indicam que o que está sendo apresentado no texto não foi plenamente observado nem concluído pelo autor. Tais expressões são geralmente empregadas quando o autor apresenta resultados supostamente novos na literatura ou as interpretações de sua pesquisa. Coracini ${ }^{13}$ ressalta que tais expressões funcionam, paradoxalmente, como estratégia de persuasão, pois “ao mostrar suas dúvidas, reticências e incertezas, o locutor transmite de si a imagem de pessoa honesta, comprometida com a verdade".

\section{Uso de vários tipos de citações e referências bibliográficas}

Mais do que em qualquer outro tipo de discurso, as vozes (ideias, dados) de outros pesquisadores se fazem presente de modo explícito no discurso científico por meio das citações e referências bibliográficas. Estas, além de exercerem inúmeras funções no texto científico, se revelam como uma forte estratégia de persuasão. ${ }^{13}$ Sobre esse aspecto, Latour ${ }^{14}$ ressalta que "uma monografia sem referências é como uma criança desacompanhada a caminhar pela noite de uma grande cidade que ela não conhece: isolada, perdida, tudo pode acontecer-lhe".

As mais comuns das citações bibliográficas são aquelas que constituem o paradigma adotado. Em geral, para começar o texto e sustentar sua pesquisa, o autor precisa de fatos bem estabelecidos e não mais questionados pela comunidade científica. Dessa forma, utiliza várias citações que situam seu trabalho dentro de um paradigma. Além disso, com esse recurso, revela o conhecimento que tem sobre o tema. ${ }^{14}$

Outro tipo de citação frequente no discurso científico e que exerce função retórica são aquelas sobre os métodos empregados na pesquisa. ${ }^{13-15}$ Ao revelar que outros cientistas já utilizaram a mesma metodologia empregada e obtiveram êxito, o autor considera-se no direito de não ser questionado sobre esse aspecto. Além disso, a apresentação deste tipo de referência desobriga o autor de fornecer muitos detalhes da metodologia, uma vez que o leitor pode consultar a obra original para obter informações adicionais.

Outro recurso retórico que o autor utiliza na tentativa de persuadir o leitor a dar crédito às suas afirmações é a citação de trabalhos anteriores feito pelo grupo sobre o mesmo tema. Esse tipo de citação informa ao leitor que a pesquisa abordada no texto foi desenvolvida por cientistas que já têm experiência sobre o tema em questão.

A citação de trabalhos de outros pesquisadores com ideias/dados que sejam semelhantes aos do autor é talvez a mais intencional das 
estratégias argumentativas empregadas pelos cientistas: além da exposição de dados que reforçam seus argumentos, o autor demonstra que o tema de sua pesquisa também desperta o interesse em outros pesquisadores. Com esse tipo de referência, o autor também se beneficia da divisão de responsabilidades juntamente com outros pesquisadores pelas informações e interpretações expostas: se existirem erros ou interpretações incoerentes no texto, ele não estará sozinho quando for julgado pela comunidade científica. ${ }^{13}$

Embora mais rara que a anterior, a citação de trabalhos de outros pesquisadores com ideias/dados conflitantes com os do autor também se faz presente nos textos científicos. Nesse caso, geralmente o autor posiciona-se contra outros autores cujas ideias sejam divergentes às suas, justificando tal posição - como é próprio do discurso científico. Essa estratégia permite que a interpretação do leitor possa mais facilmente se aproximar daquelas expressas pelo autor e ainda demonstra que este, além de estar a par da literatura de sua área, é honesto e/ ou confiante o suficiente para não omitir uma referência que poderia enfraquecer seu trabalho. ${ }^{14}$

A observação de tais exemplos deixa claro que, embora as citações e referências bibliográficas se constituam em uma exigência da comunidade científica, tal fato, no entanto, não invalida seu aspecto subjetivo e persuasivo. Ao contrário. O autor serve-se de uma convenção para melhor atingir seu objetivo: convencer o leitor da veracidade e importância de sua pesquisa. ${ }^{13}$ Latour ${ }^{14}$ acrescenta ainda que simplesmente agregar muitas referências ao discurso científico não é suficiente para torná-lo forte, pois é possível que o leitor rastreie cada referência na tentativa de comprovar até que ponto elas correspondem às colocações do autor.

\section{“Manipulação" das citações bibliográficas}

Uma análise refinada do discurso científico evidencia que outros recursos são habilidosamente acrescentados ao texto, como, por exemplo, as estratégias de "manipulação" das citações bibliográficas apresentadas. Além de garantir que os leitores fiquem "paralisados" diante da grande quantidade de referências, os autores as apresentam de tal maneira que todas estejam assentadas para seus objetivos específicos. ${ }^{14}$ Coracini ${ }^{13}$ também destaca que as citações no texto científico frequentemente representam um trabalho de reformulação, síntese e seleção do texto relatado. Dessa forma, mesmo respeitando a informação original do texto, o autor o utiliza e o manipula a serviço dos seus próprios objetivos e intenções diante da nova situação enunciativa (elaboração do novo texto). Latour ${ }^{14}$ desvela tal sutileza do discurso científico descrevendo algumas estratégias dessa natureza, como as apresentadas a seguir:

a) fortalecimento dos trabalhos similares ao do autor. Esta é talvez a estratégia de "manipulação" das citações mais frequente nos textos científicos. Nesse caso, o autor ajusta positivamente o texto relatado, dando ênfase a certos aspectos do trabalho do outro autor que ajudem a sustentar sua própria tese;

b) "ataque" às referências que possam se opor à tese do autor. Manifesta-se geralmente na forma de destaque aos pontos fracos do trabalho citado - sobretudo em relação aos dados/ideias que contrariem a pesquisa do autor - ou levantando dúvidas sobre sua validade;

c) fortalecimento de um artigo para enfraquecer outro que esteja em oposição ao trabalho do autor. Nesse caso, o cientista não critica diretamente o texto opositor à sua pesquisa, mas reforça o trabalho de outro autor cujos dados/ideias também sejam contrários ao texto opositor. Dessa forma, indiretamente, o autor consegue enfraquecer textos que estejam em oposição a seu trabalho;

d) oposição de contra-argumentos de tal maneira que um invalida o outro. $\mathrm{Na}$ existência de dois textos (ou mais) que se oponham ao trabalho do autor, mas que apresentem diferenças entre si, o autor ressalta tais discrepâncias e confronta esses textos de forma que um enfraqueça o outro. Assim, dois contra-argumentos perigosos se tornam impotentes.

O emprego cuidadoso das citações no texto científico aponta para um aspecto do discurso científico que o assemelha ao discurso político: a não imparcialidade da observação e, por isso mesmo, a seleção e ajuste das informações em função do próprio interesse do locutor. Segundo Coracini, ${ }^{13}$ "tanto o político quanto o cientista adequarão a observação aos seus interesses".

\section{Incorporação de “autoridades” (aliados superiores)}

Outra estratégia retórica também frequente nos textos científicos é a incorporação de "autoridades" no texto científico, isto é, aliados que, devido a seu reconhecido mérito na área, proporcionam crédito ao trabalho do autor. No texto esses aspectos evidenciam-se por meio dos seguintes elementos:

a) citação de autores reconhecidos na área. Ao apoiar suas afirmações em pesquisadores reconhecidos, o autor tenta assegurar que não será questionado pelo leitor, pois caso isso ocorra o leitor terá que discordar do "papa da área". Coracini, ${ }^{13}$ embora reconheça que essa visão não é muito aceita pela comunidade científica, defende que, na prática, "o uso de citações também obedece a um critério de seleção: quando houver mais de um nome a citar, escolher-se-á aquele que for mais conhecido, famoso, para assim, conseguir apoio significativo para os argumentos";

b) referências de revistas conceituadas na área. Revistas bem conceituadas pela comunidade científica geralmente têm um corpo editorial altamente exigente, contam com assessores especialistas na área e estabelecem critérios rígidos de análise e seleção dos artigos recebidos para publicação. Assim, realizar críticas a informações relatadas em revistas dessa natureza implica em questionar seu corpo editorial e assessores. Dessa forma, incorporar ao texto revistas de "autoridade" constitui um poderoso recurso persuasivo nas mãos do autor;

c) indicação das instituições que financiaram a pesquisa. Embora as próprias instituições financiadoras exijam a sua menção nas publicações decorrentes de pesquisas por elas financiadas, tal indicação pode fortalecer o texto, pois indica ao leitor que o artigo em questão é fruto de um trabalho que recebeu recursos financeiros de agências ou instituições de apoio à pesquisa e que, para isso, já teve seu mérito analisado e comprovado por outros pesquisadores.

\section{Uso de estratégias de autofortalecimento}

O discurso científico também busca reforços na própria pesquisa, revelando, dessa forma, mais uma de suas características: o uso de estratégias de autofortalecimento, isto é, justificar a pesquisa dando-se ênfase a seus aspectos positivos. Estratégias dessa natureza são observadas nos textos científicos, como:

a) indicação das aplicações da pesquisa. A utilização desse recurso implica em buscar apoio do leitor apresentando as vantagens da pesquisa, seja para ele próprio, para sua comunidade científica ou para a sociedade em geral;

b) indicação dos aspectos inovadores da pesquisa. Apresentar propostas, dados, metodologias ou conclusões inovadoras é considerado um mérito dentro da comunidade científica e, por esse motivo, os autores enfatizam as contribuições originais de sua pesquisa;

c) destaque para as evidências (provas). Uma das formas de fortalecer os argumentos é colocar o leitor não apenas diante da opinião 
do autor, mas também diante daquilo que o texto diz, agregando evidências que sustentem as conclusões. Dessa forma, a apresentação de dados da própria pesquisa na forma de figuras e tabelas, além de tornar o texto mais sucinto e didático, e, portanto, mais agradável ao leitor, serve como prova irrefutável às afirmações proferidas.

A presença desses recursos no texto evidencia também a subjetividade do discurso científico, uma vez que a listagem dos aspectos positivos da pesquisa é elaborada tanto em função do que o autor julga ser importante quanto do que supõe ser relevante para o leitor. Sobre essa questão, Latour ${ }^{14}$ ressalta que o modo mais fácil de controlar as pessoas e conseguir seu apoio é atendendo aos seus interesses. Portanto, mostrando ao leitor as vantagens da pesquisa, o autor conquista sua credibilidade e, dessa forma, também se beneficia.

Campanario ${ }^{15}$ lembra ainda que, segundo uma visão bastante tradicional, a ciência representa a busca pela verdade de maneira desinteressada e que, portanto, essa busca deveria ser por si só motivo suficiente para justificar sua atividade. Assim, o discurso científico e suas justificativas repletas de interesses que vão além da simples procura pela verdade, contrariam, pois, essa visão ingênua da ciência.

\section{ELABORAÇÃO DO MATERIAL DIDÁTICO: A RETÓRICA DA LINGUAGEM CIENTÍFICA EM FOCO}

Com base nos referenciais teóricos adotados nesta pesquisa elaboramos um material didático no qual procuramos evidenciar, sobretudo, as questões de subjetividade do texto científico e os recursos de linguagem que lhe conferem poder persuasivo. Esse material (disponível como material suplementar) foi organizado em sete atividades, conforme descrevemos a seguir.

Tomamos como ponto de partida para a elaboração do material o fato de que a padronização textual é um dos aspectos mais característico do discurso científico ${ }^{13}$ e, nesse sentido, compreender a organização e as características típicas de cada parte do texto é uma habilidade necessária aos estudantes de graduação a fim de que possam analisar os diversos tipos de documentos veiculados na literatura científica, bem como desenvolver a capacidade de elaboração de textos dessa natureza. Assim, a primeira atividade (Atividade 1) elaborada foi um exercício de "Revisão das Seções dos Textos Científicos".

Nesse exercício de revisão, foram apresentados dez recortes extraídos de distintas seções de artigos científicos das revistas Química Nova e Eclética Química para que os alunos identificassem a qual seção cada excerto pertencia e justificassem sua reposta. Em cada seção apresentada buscamos recortar trechos que evidenciassem características típicas das mesmas, de tal maneira que os alunos pudessem reconhecê-la com base em seus conhecimentos sobre tais aspectos do texto ou na relação de semelhança entre os recortes presentes no material e suas leituras de outros textos de natureza científica.

A partir da Atividade 2, denominada "Os Aliados dos Textos Científicos", iniciamos especificamente a abordagem dos aspectos retóricos da linguagem científica. Para sua elaboração partimos da concepção de Latour $^{14}$ de que o discurso científico é uma espécie de batalha entre o autor do texto científico e um leitor discordante. Assim, para resistir às objeções do leitor e conseguir convencê-lo da relevância e veracidade da pesquisa apresentada, o autor reúne no texto uma série de aliados ou elementos textuais que têm força retórica. Com base em tais considerações, destacamos na Atividade 2 a presença no texto dos seguintes elementos: citações de artigos presentes em revistas de credibilidade no meio; citações de autores reconhecidos na área em que a pesquisa se insere; citações de trabalhos de outros autores que também investigam a mesma temática e, indicação de instituições financiadoras.

A abordagem de questões dessa natureza possibilita ao estudante não somente reconhecer estratégias de linguagem que podem fortalecer um texto científico, mas, especialmente, refletir sobre questões que permeiam a prática da ciência (como "autoridade", "prestígio", "temas de interesse na ciência", "avaliação por pares") e que exercem influência na percepção tanto de quem dela faz parte quanto do grande público.

Além desses aliados "externos", também ressaltamos na Atividade 2 os aliados "internos", isto é, elementos retóricos oriundos do próprio grupo de pesquisa ou trabalho, tais como, indicação de publicações anteriores do próprio grupo relacionados ao tema em foco e, indicação ou destaque aos aspectos inovadores do trabalho. Tais aliados são também estratégias de autofortalecimento e sua presença no texto científico o fortalece na medida em que demonstra para o leitor que o autor já tem experiência no assunto em foco e que outros estudos na mesma linha de pesquisa já foram aprovados pelos pares. ${ }^{13}$ Outro aspecto valorizado pela comunidade científica e, por consequência, empregado como recurso retórico é a indicação explícita no texto de que o trabalho relatado é uma contribuição original à literatura da área. ${ }^{15}$

A fim de possibilitar uma melhor compreensão e visualização dos assuntos abordados, apresentamos também exemplos de como esses recursos se evidenciam nos textos científicos, dando especial destaque àqueles da área de Química. Na Figura 1 ilustramos um dos exemplos apresentados no material, no qual destacamos a característica da linguagem científica que foi abordada e um trecho de um artigo científico publicado na Química Nova em que tal aspecto poderia ser observado pelo aluno. Esse recurso foi amplamente empregado na elaboração do material didático.

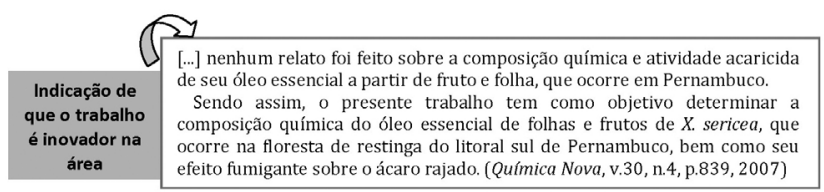

Figura 1. Trecho de um artigo científico da área de Química empregado para exemplificar uma das estratégias retóricas abordadas na Atividade 2

A Atividade 3, denominada "A Presença do Autor nos Textos Científicos", tem a intenção de desmitificar uma das características mais difundidas a respeito da linguagem científica dentro da comunidade acadêmica: a de que esta é totalmente objetiva, impessoal, neutra. Muitos livros e manuais sobre redação de textos científicos reforçam essa concepção, recomendando o uso de recursos de linguagem que tornem o texto o mais impessoal possível. ${ }^{12,17}$

Essas práticas, segundo Coracini, ${ }^{13}$ têm a função de apagamento do sujeito enunciador, transmitindo ao leitor uma imagem de imparcialidade do autor diante de seu objeto de pesquisa e, por esse motivo, garantindo credibilidade ao texto científico. No entanto, conforme Latour, ${ }^{14}$ "embora se diga que a literatura técnica é impessoal, isso está longe de acontecer. Os autores estão por toda parte, incorporados no texto", denunciando sua subjetividade. Portanto, evidenciar a presença do autor no texto científico, além de ser algo pouco comum em materiais didáticos destinados aos estudantes de cursos da área de ciências, contraria muitas das ideias já sedimentadas nessa comunidade, permitindo-lhes novas formas de "ler" o texto.

As considerações de Coracini ${ }^{13}$ e Campanario ${ }^{15}$ sobre as marcas deixadas pelos autores no discurso científico subsidiaram a elaboração desta parte do material didático, no qual apresentamos aos alunos algumas situações que indicam no texto a presença do autor, como, por exemplo, quando este: assume sua pesquisa, justificando a escolha do tema ou do material; opina sobre os fatos ou resultados obtidos; avalia o trabalho e sugere, novas pesquisas; faz hipóteses, suposições; chama a atenção do seu interlocutor para algum aspecto 
ou fato em particular; admite limitações na pesquisa ou ignorância sobre determinado assunto e, utiliza expressões que denotam dúvidas ou incertezas sobre os resultados.

Além de destacar as marcas de subjetividade do discurso científico, acrescentamos ao material a indicação da seção do texto científico em que tais aspectos comumente estão presentes, bem como exemplos oriundos de artigos científicos da área de Química. A maneira como tais informações foram articuladas no material está ilustrada na Figura 2.

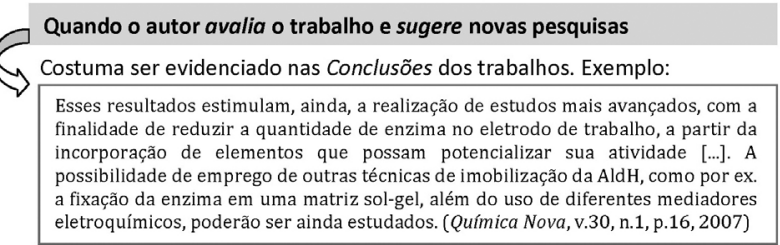

Figura 2. Trecho da Atividade 3, no qual se exemplifica um dos elementos que evidenciam a presença do autor no texto científico

Na Atividade 4, "Tipos de Citações Presentes em Textos Científicos", abordamos um aspecto bastante característico dos textos científicos: a presença de citações bibliográficas, isto é, as múltiplas vozes (ideias, dados) de outros pesquisadores se fazem presente de modo explícito no discurso científico. Esse aspecto da linguagem científica a priori não se constitui em novidade para muitos dos estudantes de graduação da área de ciências, pois é uma prática amplamente empregada na construção dos textos científicos. Para Oliveira e Queiroz, ${ }^{12}$ as inúmeras citações e referências bibliográficas refletem ainda o fato de que um cientista raramente está sozinho na produção de novos conhecimentos, ou seja, colocam em evidência o processo social de construção da ciência.

No entanto, nosso objetivo nesta parte do material didático não foi apenas apresentar aos alunos citações bibliográficas que comumente permeiam o discurso científico e as seções do texto onde geralmente são inseridas, mas também discutir a importância retórica de tais citações, isto é, de que maneira cada uma delas pode contribuir no sentido de persuadir o leitor a dar credibilidade ao autor e à sua pesquisa. Os principais tipos de citações bibliográficas presentes em artigos científicos que abordamos na Atividade 4 foram: citações que constituem o paradigma adotado pelo autor (informações consolidadas); citações de trabalhos anteriores realizados pelo próprio grupo; citações que apresentam o método utilizado; citações de trabalhos com resultados semelhantes e citações de trabalhos com resultados discordantes.

Embora algumas dessas citações já tivessem sido discutidas de forma isolada e sob outros enfoques na Atividade 2 ("Os Aliados dos Textos Científicos"), na Atividade 4 objetivamos agrupá-las a fim de propiciar aos alunos uma visão integrada e sistemática de algumas das diversas citações que compõem um artigo científico e, ao mesmo tempo, ajudá-los a reconhecer e comparar tanto sua distribuição entre as seções do texto como a maneira pela qual cada uma delas exerce poder persuasivo sobre o leitor.

Para a Atividade 5, "Trabalhando com as Citações nos Textos Científicos", adotamos as considerações de Latour ${ }^{14}$ sobre as estratégias de linguagem relacionadas à maneira como as citações são cuidadosamente empregadas nos textos científicos. Dessa forma, os recursos retóricos de "manipulação" das citações abordados nesta parte do material foram: fortalecer os aliados dando destaque a trabalhos similares aos do autor; enfatizar que os métodos usados na pesquisa são também utilizados por outros autores; atacar (se for conveniente) as referências que possam se opor ao trabalho do autor e fortalecer um artigo para enfraquecer um outro que esteja em oposição ao trabalho do autor.
Para facilitar o reconhecimento por parte dos alunos de tais estratégias no texto científico, incluímos alguns trechos oriundos de artigos da área de Química nos quais, ainda que sutilmente, esses recursos pareciam estar presentes. A Figura 3 ilustra um trecho desse material nas quais essas características podem ser observadas.

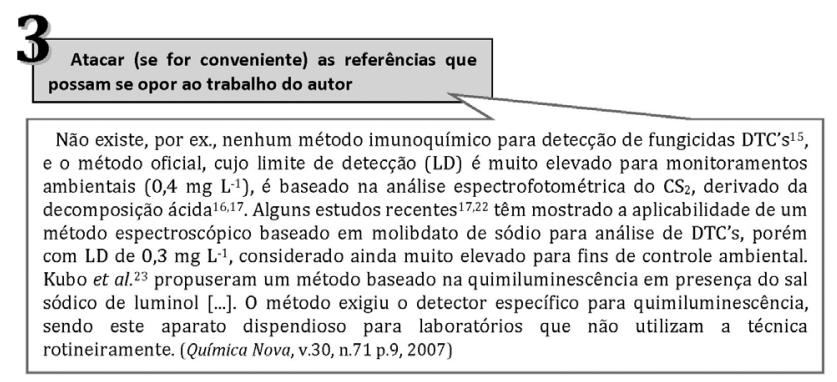

Figura 3. Trecho da Atividade 5, no qual se destaca e exemplifica uma das estratégias retóricas de "manipulação" das citações bibliográficas

No intuito de estimular os alunos a refletirem sobre esse aspecto da linguagem científica apresentamos ainda nesta atividade uma citação de Latour, ${ }^{14}$ onde estabelece uma analogia entre o discurso científico e o discurso político (Figura 4). Esta é uma forma pouco comum de se enxergar a linguagem científica, dentro da própria comunidade ou, até mesmo, fora dela. Assim, apresentar tais ideias aos graduandos é levar algo novo e possivelmente contrário à maioria das noções que eles têm sobre ciência e sua linguagem.

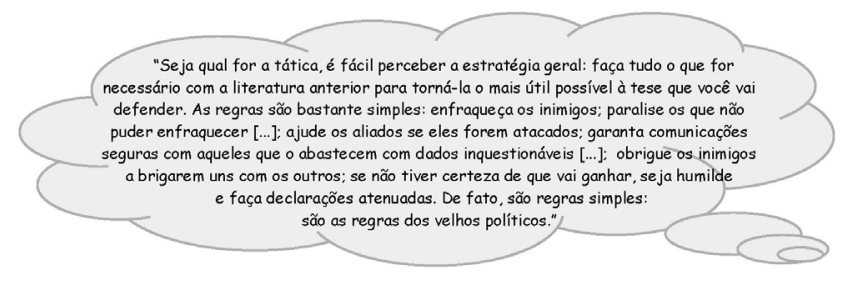

Figura 4. Trecho da Atividade 5, no qual se apresenta uma citação de Latour, ${ }^{14}$ em que o autor compara o discurso científico com o discurso político

Na Atividade 6, "A Produção do Texto e o Foco no Leitor", buscamos evidenciar algumas características da linguagem científica que demonstram que o discurso científico é construído no sentido de agradar, conduzir, atender aos anseios do leitor. Para abordar como tal aspecto se manifesta no texto científico, tomamos inicialmente como base as considerações de Coracini ${ }^{13}$ sobre o fato de que a sequência das seções na qual o texto científico é apresentado ao leitor é frequentemente bem distinta daquela empregada pelo autor quando da sua redação. Nessa perspectiva, descrevemos no material didático, em formato de fluxograma, tanto a sequência das seções observada pelo leitor quanto aquela frequentemente seguida pelo autor na elaboração do texto. O intuito dessa abordagem foi demonstrar aos alunos que a própria estrutura do texto é moldada de forma a garantir uma leitura lógica e agradável para o leitor, revelando sua importância na construção do discurso da ciência.

Outra questão abordada na Atividade 6 foi o emprego de estratégias de direcionamento ao leitor, seja por meio do uso de expressões para despertar sua atenção para aspectos que o autor julga relevante ${ }^{13}$ ou por meio do uso de instruções ou diretrizes que conduzam o leitor a percorrer no texto o caminho desejado pelo autor. ${ }^{14,15}$ A Figura 5 ilustra como um desses recursos foi citado e exemplificado no material didático.

Outro ponto que mereceu destaque nesta atividade foi a discussão sobre a presença no texto científico de respostas antecipadas do autor 


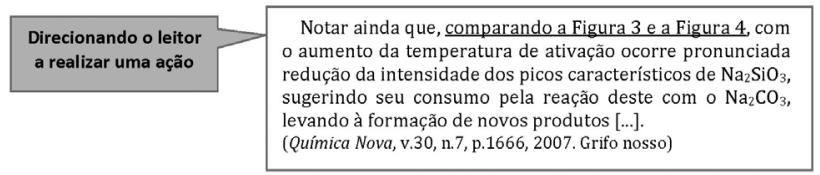

Figura 5. Trecho da Atividade 6, no qual se apresenta um exemplo de direcionamento ao leitor

às supostas objeções do leitor. Para elaborar essa parte do material nos pautamos principalmente nas considerações de Latour ${ }^{14}$ sobre os possíveis contra-argumentos do leitor e as inúmeras provas e respostas acrescentadas pelo autor na construção do discurso científico.

Na última parte do material didático ressaltamos outra questão que perpassa todo o discurso científico - a oscilação entre "Cautela e Audácia no Texto Científico" (Atividade 7). Com base nos estudos de Coracini ${ }^{13}$ e Campanario ${ }^{15}$ foi possível delinear e transpor para o material tanto as situações nas quais os autores fazem uso de afirmações atenuadas quanto os recursos linguísticos empregados para transmitir a imagem de cautela nas informações expressas no discurso científico. Complementando tais considerações, Latour ${ }^{14}$ afirma que o texto científico, na verdade, "ziguezagueia" entre cautela e audácia. Descreve, então, situações nas quais não há meias afirmações e, portanto, a assertividade é predominante. Apresentamos nesta parte do material tanto exemplos nos quais os autores são cautelosos quanto são assertivos.

Tais aspectos do texto científico contrariam uma visão comum entre os estudantes de ciências: a de que o discurso científico sempre se traduz em certezas. ${ }^{13}$ Dessa forma, acreditamos que o material didático possibilita aos estudantes reconhecer e aceitar a dúvida, a suposição, as palavras atenuadas como sendo características da linguagem da ciência.

\section{CONSIDERAÇÕES FINAIS}

Este trabalho partiu do princípio de que uma compreensão mais profunda dos recursos retóricos presentes no discurso científico é um passo importante para aqueles que lêem, escrevem ou fazem ciência - como é o caso dos estudantes de graduação em Química. Nesta perspectiva, o material didático produzido, no qual delineamos vários recursos retóricos presentes em textos científicos dessa área, se apresenta como ferramenta potencialmente capaz de desenvolver nos alunos a capacidade de ler e analisar os textos de forma mais crítica. O conhecimento de tais recursos pode ainda auxiliá-los na produção de seus próprios textos.

Embora originalmente este material tenha sido elaborado para estudantes de graduação em Química, acreditamos que também possa ser utilizado por pós-graduandos, uma vez que tais estratégias da linguagem científica raramente são abordadas nos cursos de graduação em Química. Por tratar de características da linguagem que não são exclusivas dos textos de Química, acreditamos que este material também possa ser útil a estudantes de outras áreas da ciência.

A abordagem deste material pode ser realizada tanto em disciplinas que tratam de aspectos específicos da produção de textos ou ainda em disciplinas diversas do currículo de Química (ou de outras áreas da ciência), uma vez que sua organização em atividades curtas possibilita a aplicação tanto em sala de aula quanto em atividades extraclasse. Cabe destacar que, dando continuidade a esta pesquisa, esse material didático foi aplicado na disciplina teórica Química Orgânica I, oferecida no terceiro semestre do Curso de Bacharelado em Química do Instituto de Química de São Carlos, Universidade de São Paulo, Brasil. Resultados da análise de produções escritas dos estudantes decorrentes de sua aplicação foram publicados na Revista Alexandria. ${ }^{18}$

\section{MATERIAL SUPLEMENTAR}

O material didático sobre os aspectos retóricos da linguagem científica encontra-se disponível gratuitamente em http://quimicanova.sbq.org.br, na forma de arquivo PDF.

\section{AGRADECIMENTOS}

À CAPES e FAPESP (Processo 2011/06555-9) pelo auxílio financeiro.

\section{REFERÊNCIAS}

1. Lemke, J. L.; Aprender a Hablar Ciencia, Paidós: Buenos Aires, 1997.

2. Villani, C. E. P.; Nascimento, S. S.; Investigações em Ensino de Ciências 2003, 8, 187.

3. Florence, M. K.; Yore, L. D.; J. Res. Sci. Teach. 2004, 41, 637.

4. Gunel, M.; Hand, B.; Prain, V.; Int. J. Sci. Math. Educ. 2007, 5, 615.

5. Massi, L.; Abreu, L. N.; Queiroz, S. L.; Revista Electrónica de Enseñanza de las Ciencias 2008, 7, 704.

6. Zucco, C.; Pessine, F. B. P.; de Andrade, J. B.; Quim. Nova 1999, 22, 454.

7. Luz Jr., G. E.; Sousa, S. A.; Moita, G. C.; Moita Neto, J. M.; Quim. Nova 2004, 27, 164.

8. Santos, G. R.; Queiroz, S. L.; Ciência e Educação 2007, 13, 193.

9. Mabrouk, P. A.; J. Chem. Educ. 2001, 78, 1628; Tilstra, L.; J. Chem. Educ. 2001, 78, 762; Schepmann, H. G.; Hughes, L. A.; J. Chem. Educ. 2006, 83, 1024; Robinson, M. S.; Stoller, F. L.; Horn, B.; Grabe, W.; J. Chem. Educ. 2009, 86, 45.

10. Spector, N.; Manual para Redação de Teses, Projetos de Pesquisa e Artigos científicos, Guanabara Koogan: Rio de Janeiro, 2001; Cyranka, L. F. M.; Souza, V. P.; Orientações para Normalização de Trabalhos Acadêmicos, Editora da UFJF: Juiz de Fora, 2004.

11. Abrahamsohn, P.; Redação Científica, Guanabara Koogan: Rio de Janeiro, 2004.

12. Oliveira, J. R. S.; Queiroz, S. L.; Comunicação e Linguagem Científica: guia para estudantes de química, Editora Átomo: Campinas, 2007.

13. Coracini, M. J.; Um Fazer Persuasivo: o discurso subjetivo da ciência, Editora Pontes: Campinas, 2007.

14. Latour, B.; Ciência em Ação: como seguir cientistas e engenheiros sociedade afora, Editora UNESP: São Paulo, 2000.

15. Campanario, J. M.; Enseñanza de las Ciencias 2004, 22, 365.

16. Oliveira, J. R. S.; Batista, A. A.; Queiroz, S. L.; Quim. Nova 2010, 33, 1980.

17. Gilpin, A. A.; Patchet-Golubev, P.; A Guide to Writing in the Sciences, University of Toronto Press: Toronto, 2000; Jardine, F. H.; How to do your Student Project in Chemistry, Chapman \& Hall: London, 1994.

18. Oliveira, J. R. S.; Queiroz, S. L.; Alexandria: Revista de Educação em Ciência e Tecnologia 2011, 4, 89. 